\title{
Género y memoria: El álbum familiar como huella autobiográfica
}




\section{GENDER AND MEMORY: THE FAMILY ALBUM AS AN AUTOBIOGRAPHICAL MARK}

\section{ABSTRACT}

On this paper we would like to show how memory, in any of its varieties, forms an essential part of current artistic discourse and practice. For this, we will focus on the importance of autobiographical narration and its manifestation from the works of artists who work around the family album. We will analyze how this type of photographic archive has been used and reconfigured by artists who have wanted to express their own experiences from a gender perspective. Personal memory interacts with narratives that concern collective memory, where the hegemonic stories that have come down to us have tried to silence these stories. However, art has given voice to themes such as the body and female sexuality, experiences derived from diseases such as cancer or trauma suffered by relatives of dictatorships in certain contemporary societies and which have led to the application of concepts such as postmemory.

\section{Keywords}

memory, autobiography, postmemory, family album, gender.

\section{RESUMEN}

En el presente artículo quisiéramos mostrar como la memoria, en cualquiera de sus variedades, forma una parte imprescindible de los discursos y la práctica artística actual. Para ello, nos centraremos en la importancia de la narración autobiográfica y su manifestación a partir de las obras de artistas que trabajan en torno al álbum familiar. Analizaremos como este tipo de archivo fotográfico se ha utilizado y reconfigurado por artistas que han querido manifestar sus propias experiencias desde una perspectiva de género. La memoria personal interactúa con narrativas que atañen a la memoria colectiva, donde los relatos hegemónicos que nos han llegado han tratado de silenciar estas historias. Sin embargo, el arte ha dado voz a temáticas como el cuerpo y la sexualidad femenina, experiencias derivadas de enfermedades como el cáncer o traumas sufridos por familiares de dictaduras de ciertas sociedades contemporáneas y que han dado lugar a la aplicación de conceptos como el de postmemoria.

\section{Palabras clave}

memoria, autobiografía, postmemoria, álbum familiar, género. 


\section{INTRODUCCIÓN}

Una de las principales características de la memoria es el carácter mutable de los recuerdos debido, entre otras razones, al irremediable paso del tiempo. No va a importar el grado de fiabilidad, amplitud de los recuerdos o de si corresponden a acontecimientos que atañen a una colectividad o bien, a momentos pequeños y privados. Todas estas posibilidades van a afectar a la forma en la que recordamos.

De acuerdo con la filósofa académica Mary Warnock durante el siglo XVII, el Empirismo británico introdujo innovaciones a la hora de concebir la memoria, ya que para esta corriente filosófica la memoria es una forma de conocimiento basada en la experiencia (Warnock, 1987). Uno de los representantes de esta corriente filosófica es David Hume, el cual en su Tratado de la naturaleza humana (1738) expone su teoría del conocimiento basado en la experimentación a partir de las percepciones que tenemos del mundo, distinguiendo entre:

(...) dos géneros distintos que yo llamo impresiones e ideas. La diferencia entre ellos consiste en los grados de fuerza y vivacidad con que se presentan a nuestro espíritu y se abren camino en nuestro pensamiento y conciencia. A las percepciones que penetran con más fuerza y violencia llamamos impresiones, y comprendemos bajo este nombre todas nuestras sensaciones, pasiones y emociones tal como hacen su primera aparición en el alma. Por ideas entiendo las imágenes débiles de éstas en el pensamiento y razonamiento (...) (Hume, 2001, p. 20)

Más adelante vuelve a hacer otra distinción dentro de las ideas y son las que surgen de la memoria y la imaginación:

Hallamos por experiencia que cuando una impresión ha estado una vez presente al espíritu, hace de nuevo su aparición en él como una idea, y que esto puede suceder de dos modos diferentes: cuando en su nueva aparición conserva un grado considerable de su primera vivacidad y es así algo intermedio entre una impresión y una idea y cuando pierde enteramente esta vivacidad y es una idea por completo. La facultad por la que reproducimos nuestras impresiones del primer modo es llamada memoria, y aquella que las reproduce del segundo, imaginación. (Hume, 2001, p. 22)

A pesar de esta distinción que se hace desde el empirismo, se hace difícil separar aquello que inicialmente estaba almacenado en nuestra memoria de aquello que es producto de la imaginación, la cual tiende a rellenar las lagunas de datos que van apareciendo en los recuerdos y a modificar los hechos, dulcificándolos o dramatizándolos.

Posterior a esta corriente existirán otras formas de concebir la memoria. Sin embargo, no siempre ha estado presente en los debates filosóficos y artísticos con igual intensidad. De acuerdo con el historiador político-cultural Enzo Traverso, esta preocupación por la memoria es reciente ya que entre las décadas de los 50 y 70 del siglo XX estaba ausente en los debates intelectuales:

(...) la represión por décadas de una visibilidad y de un reconocimiento de las víctimas produce un fenómeno reactivo de hiper-visibilización, o de obsesión retrospectiva, hay una especie de compensación memorial del silencio que ocultó esos genocidios durante décadas. Traverso (como se citó en Millán, 2016 p. 277) 
El naciente interés por la memoria se debe de acuerdo M. Paula González y Joan Pagès (2014) a la aparición de tres "giros" fundamentales que repercutirán en el terreno del pensamiento y de la creación artística. Dichos cambios son: el giro al pasado, el giro lingüístico y el giro subjetivo.

El primero de estos virajes fue teorizado, entre otros por el filólogo y crítico cultural Andreas Huyssen. Tras las grandes tragedias del siglo $X X$, como guerras e intentos de aniquilar determinadas etnias y razas, este giro no pone el foco de atención en el futuro sino en la conservación del pasado:

El giro hacia los residuos de culturas ancestrales y tradiciones locales, el privilegio de lo no-sincrónico y heterogéneo, el deseo de conservar, de prestar un aura histórica a objetos que de otro modo estarían condenados al desecho, a la obsolescencia: todo eso puede efectivamente leerse como reacción frente a la velocidad acelerada de la modernización (...) (Huyssen, 2002, p. 24)

El segundo de los giros es el lingüístico. Este concepto reconsidera el lenguaje y la narración como elementos configuradores de la historiografía. El cambio aparece como resultado de una crisis y un replanteamiento de corrientes filosóficas como el estructuralismo y marxismo. En este cambio se cuestionó los grandes relatos y se decantó por una aproximación a los pequeños detalles y a los relatos excepcionales que hasta entonces se habían ignorado porque procedían de la cultura popular, la vida cotidiana y la mujer (González y Pagés, 2014). Los representantes de este giro poseen muchos posicionamientos al respecto, entre los que podríamos destacar al filósofo Hayden V. White y su obra Metahistoria. La imaginación histórica en la Europa del siglo XIX (1973) donde considera que la historia y cualquier actividad cultural incluye elementos narrativos, a pesar de que el empleo de los mismo pueda dar interpretaciones poco fiables: “(...) en la medida en que esta representación se parezca a los acontecimientos que presenta, puede considerarse una narración verdadera" (White, 1992, p. 43).

Y por el último, e influenciado por el giro lingüístico, apareció el giro subjetivo. Donde da protagonismo a aquellos protagonistas silenciados por los relatos hegemónicos teniendo en cuenta el pasado más cercano y un punto de vista muy particular de cómo se vivieron algunos acontecimientos históricos. El nombre de este giro fue acuñado por la ensayista Beatriz Sarlo en Tiempo pasado. Cultura de la memoria y giro subjetivo. Una discusión (2005):

El pasado vuelve como cuadro de costumbres donde se valoran los detalles, las originalidades, la excepción a la norma, las curiosidades que ya no se encuentran en el presente. Como se trata de vida cotidiana, las mujeres (especialistas en esa dimensión de lo privado y lo público) ocupan una porción relevante del cuadro. Estos sujetos marginales, que habrían sido relativamente ignorados en otros modos de la narración del pasado, plantean nuevas exigencias de método e inclinan a la escucha sistemática de los "discursos de memoria": diarios, cartas, consejos, oraciones. (Sarlo, 2005, p. 19)

Con esta puesta en valor de los relatos pertenecientes a la memoria personal y autobiográfica por parte de testigos marginales como han sido las mujeres se contribuye a elaborar una nueva forma de contar la historia que cuestiona los grandes relatos hegemónicos cuyos protagonistas han sido los vencedores debido a su punto de vista parcial y favorecedor de determinadas ideologías.

La conexión existente entre la memoria y el género ha sido abordada Leyla Troncoso y Isabel 
Piper que tratan de vincularla con la identidad, debido a que: "Es a través de determinadas prácticas de memoria que nos damos sentido a nosotras mismas como sujetas sociales, y que construimos sentidos de pertenencia y diferencia que dotan de cierta coherencia a nuestras identidades que son a su vez siempre generizadas" (Troncoso y Piper, 2015, p.67). Tal es así que algunos colectivos feministas realizaron una serie de trabajos relacionado con la memoria como la formación de grupos de toma de consciencia en los que se trataba de que las mujeres repensaran sus experiencias vitales mediante "un proceso participativo, promovían la re-significación de las vivencias biográficas de las mujeres y la toma de conciencia de sus experiencias de sexismo y dominación masculina" (Troncoso y Piper, 2015, p.74). O bien desde el ámbito académico se promovió el denominado Memory Work a cargo de la psicóloga social Frigga Haug en 1987 con la intención de "visibilizar las experiencias de quienes han sido marginadas o patologizadas por las investigaciones psicológicas, para luego re-significar, interrogar y transformar estas experiencias hegemonizadoras y sus efectos en las vidas de las personas" (Troncoso y Piper, 2015, p.75).

A pesar de este contexto y de la puesta en valor de la memoria, no existen muchos manuales especializados que se aventuren a analizar las prácticas artísticas contemporáneas. Es por ello por lo que quisiéramos destacar principalmente el trabajo de dos autoras dentro de los cuales se hace referencia a obras realizadas por mujeres y en los que se aprecian su implicación por la preservación de la memoria.

Por un lado, Lisa Saltzman con su libro Making Memory Matter. Strategies of Remembrance in Contemporary Art (2006). Saltzman parte de la obra La Doncella Corintia (1782-84) de Joseph Wright de Debray, la cual está basada en el relato que narra el origen de la pintura de Plinio el Viejo en su Historia Natural. En dicha historia aparece una doncella corintia que ante la partida a la guerra de su amado aprovecha un momento en el que queda dormido para registrar la sombra de su perfil en la pared. Dicha silueta fue posteriormente rellenada con barro por su padre que era alfarero, realizando así un retrato en relieve. Saltzman comenta al respecto:

Una llama luminosa como medio para proyectar la sombra del cuerpo ante ella, un contorno dibujado como un medio para capturar la imagen evanescente de ese cuerpo, un molde escultórico como un medio para reconstituir y concretizar algo de ese cuerpo perdido: en el cuento de Plinio, por mucho que podamos ver las semillas de una forma de representación icónica, a saber, el dibujo y la pintura figurativa, también se nos presenta un arte de la indización, con estrategias de representación que estructuran el objeto visual como el rastro material de un cuerpo fugitivo. (Saltzman, 2006, pp. 2-3)

A partir de esta obra Saltzman considera el origen de la representación plástica como una historia basada en ausencias que se convierte en motor creativo:

\section{(...) la historia de la doncella corintia puede ser enormemente productiva como paradigma para considerar el arte del presente. Una historia en la que la ausencia anticipada inspira y fundamenta el nacimiento de la representación pictórica, y luego escultórica, del cuento de Plinio. Siente ese momento mítico cuando la pérdida inminente impulsa el impulso de grabar y recordar. (Saltzman, 2006, p. 2)}

Es por ello por lo que a partir de los elementos que la componen, agrupa una selección de obras en tres tipologías: Proyecciones, Siluetas y Vaciados. Observamos, pues, unos trabajos basados en una serie de ausencias presentes y para ello los artistas se sirven de la luz, la sombra en 
forma de siluetas y el vestigio para elaborar sus propuestas. Justo como sucede en el relato que narra la pintura.

Por otro lado, encontramos a Joan Gibbons y su libro Contemporary art and Memory. Images of Recollection and Remembrance (2007). Esta autora indica que a partir de la década de 1980 la memoria ha sufrido un descrédito, dada la falta de exactitud y objetividad que se ha predicado a través del Ilamado "síndrome de la falsa memoria" (Gibbons, 2007, p. 4), consistente en la acumulación de un alto número de recuerdos que son conservados de una forma muy real, pero en realidad no sucedieron de esa forma. Este tipo de manifestación suelen acontecer debido a la vivencia de episodios traumáticos vividos de manera individual, que suelen contraponerse con los relatos oficiales procedentes de la historia y de la memoria colectiva. El arte ha tratado de ser un soporte para estos tipos de narraciones paralelas, actuando como altavoz de dichas versiones alternativas, aunque ello supusiera contradecir el punto de vista de quienes escribieron los libros de historia -habitualmente los triunfadores.

Gibbons hace una taxonomía de las prácticas artísticas contemporáneas considerando seis tipologías. Sin embargo, hemos decir que los trabajos de los que se sirve u otros que pudiéramos encontrar podrían pertenecer a varias de estas tipologías. Entre ellas encontramos en primer lugar, obras basadas en la exteriorización de la Autobiografía a partir del autorretrato; obras configuradas a través de Huellas y vestigios del pasado; Reconstrucciones de historias que atañen a la memoria colectiva, recurriendo al collage y al ensamblaje de fragmentos; la Postmemoria o la memoria de los nacidos después de determinados episodios traumáticos, como la II Guerra Mundial; Recreaciones de episodios pertenecientes a la memoria episódica, donde los artistas cuentan con una implicación social de algún para escenificar algún acontecimiento del pasado y por último, la práctica del Archivo en los que vemos colecciones de objetos que atañen tanto a la memoria colectiva como individual. De hecho, podemos encontrarnos trabajos dentro de esta categoría en los que los artistas evidencian una práctica casi enfermiza por coleccionar y ordenar determinados tipos de objetos. Para concluir y tras argumentar estas seis categorías, añade un epílogo final a su libro, y aborda el Olvido como tema ejemplificado por obras que destruyen toda clase de objeto o vestigio o bien a la desaparición de cualquier recuerdo a causa del Alzheimer.

Como vemos, la memoria puede ser no solo una vía de reconocimiento personal, sino también un medio a través del cual desarrollar la imaginación. Esta conjunción entre lo privado y lo público a partir de la memoria va a ser una constante en las prácticas artísticas como el dibujo, la pintura y la fotografía a partir del siglo XX, un terreno en el que se van a evidenciar claramente dos tipos de memoria: la memoria voluntaria (aquella que produce imágenes a partir de la apariencia externa de las cosas) y la memoria involuntaria (que surge de manera azarosa a partir de las emociones y sensaciones que desprenden determinados estímulos y que van más allá del intelecto y la razón).

A continuación, realizaremos un recorrido por determinados tipos de obras cuyo germen es autobiográfico. Por un lado, vamos a encontrar el género del autorretrato como una suerte de expresión de nuestra mitología individual. Por otro lado, veremos cómo esas autoficciones han encontrado como canal de expresión una de las categorías argumentadas por Gibbons como es el del archivo, en nuestro caso de corte fotográfico, como es el álbum familiar. Concretamente en los que están realizados por mujeres y evidencian cuestiones de género como su papel en la sociedad o exteriorizan alguna clase de episodios traumáticos propios o ajenos. 
El significado etimológico de la palabra biografía es escrito o escritura sobre la vida (bios 'vida' y graphía, 'escritura') o, en otras palabras, el relato, más o menos verídico, de una vida. Si además se le añade el prefijo auto, se está indicando que ese relato pertenece y es contado por la misma persona.

La memoria autobiográfica abarca los recuerdos que poseemos de nosotros mismos y de nuestras relaciones con nuestro entorno. En el campo de la psicología los estudios sobre este tipo de memoria son relativamente recientes. Uno de los especialistas que se dedicaron en desarrollar la memoria autobiográfica de manera teórica fue Martin Conway (2005), considerándola como el sistema que mantiene el conocimiento sobre el yo experiencial. El contenido albergado en nuestra memoria siempre va a partir de él, aunque no siempre vaya acompañado de una experiencia recordada (Conway et al., 2002).

Uno de los aspectos más importantes que van a dar lugar a la génesis y expansión de las artes durante el siglo XX va a ser el de la construcción de una identidad individual y biografía a partir de un relato mítico, como predijo, entre otros, André Breton (Borja-Villel, 2013). Esta construcción biográfica que realiza el propio artista bebe de las fuentes de la historia o bien del estímulo y las impresiones que le causa su propio entorno vital. Por ello, dada la multiplicidad y variedad de esas fuentes, las formas de desarrollo y el contenido de sus discursos creativos resultan de lo más variopintos. Los artistas van a construir una serie de obras que, en cierta forma, podrían ser considerados fetiches, debido a que condensan estratos de tiempo y vivencias con significaciones relevantes. Teniendo en cuenta todo lo anterior y dependiendo del grado de veracidad de esas narraciones artísticas, nos encontraremos con una amplia gama de relatos, que podrían ir desde la recreación fiel y documentada de un acontecimiento hasta el empleo de hechos del todo ficticios. Como indica Jean François Chevrier, en el arte moderno se va a producir un cruce de confluencias entre dos parámetros contradictorios de la narración, "la referencia a los hechos (los 'pequeños hechos verdaderos' de Stendhal) y la remanencia del mito" (Chevrier, 2013, pp. 22-23), lo que viene a converger en la idea de mitología individual.

La expresión mitología individual arraigó en el seno de la crítica artística durante los años setenta, si bien su empleo se remite tiempo atrás. La idea que aborda este concepto fue desarrollada en la década de los treinta por el crítico literario Albert Béguin, quien usó ese binomio conceptual para hablar de la obra de Gérard Nerval:

Una sociedad ficticia, cuando es obra de un gran artista, surge en un punto en el que se encuentran dos proyecciones diferentes: la proyección en el imaginario de un mundo real que el novelista ha registrado lo mejor que puede: y la proyección de un mito personal, expresando su autoconocimiento del destino, su noción de las fuerzas materiales y espirituales cuyo campo es el ser humano. (Béguin, 1952, p. 13)

Años más tarde, en 1963, Harald Szeemann usó ese mismo término para hablar de la obra del artista Étienne Martin, a colación de una exposición que estaba teniendo lugar en el Kunsthalle de Berna. Finalmente sería el propio Szeemann quien asentara el término, al volver a emplearlo para hacer referencia a una sección de la Documenta 5 (1972) que incluía obras de diferente procedencia. 
El concepto de mitología individual apareció inicialmente asociada a la literatura con Nerval y Rimbaud. Basta leer el poema de Rimbaud Una temporada en el Infierno (1873) para entender el modo en el que la convulsa vida del poeta asoma entre sus líneas (esos "pequeños hechos verdaderos"). El propio Rimbaud (2006) escribiría: "Me parecía que a cada ser le eran debidas otras vidas" (p. 10) que evidencia su pretensión de crear un juego de identidades a partir de la configuración de un lirismo biográfico ficticio alrededor de su persona. En el caso de la pintura, un claro exponente de esas mitologías individuales será Leonora Carrington. En ella se puede observar cómo su trabajo le sirvió para crear un mundo propio y onírico que atestigua ciertos traumas psíquicos. Estos problemas se agravaron con una gran crisis nerviosa que llevó a su padre a internarla en un hospital psiquiátrico de Santander. Este episodio se produjo tras conocer que su esposo Max Ernst había sido internado en un campo de concentración nací para extranjeros. Del recuerdo de su estancia en este hospital, Carrington escribió el libro Memorias de abajo (1937) y posteriormente le sirvió para realizar una pintura homónima al libro. En este cuadro se observan una serie de personajes fantásticos en mitad de un jardín, posiblemente una recreación de los jardines del hospital psiquiátrico y en donde destacamos un caballo, considerado una suerte de alter-ego de la artista y que podemos apreciar en otras obras como el autorretrato titulado La posada del caballo del alba (1936-37).

En consecuencia, podemos afirmar que la idea de mitología individual viene a ampliar los registros de la narración biográfica y autobiográfica, ya que incorpora a la narración reconstrucciones basadas en leyendas que beben de los relatos mitológicos, pero también a las propias determinaciones que tradicionalmente venían asociadas con la redacción de lo biográfico. Es más, la narración, de acuerdo con Chevrier, posee ciertas semejanzas con el mito y con el ensamblaje, debido a que el artista trabaja con documentos de diferente índole, los cuales reúne, ordena y recompone con objeto de dar forma a un relato personal. Sin embargo, a pesar de que desde la Antigüedad ha existido cierto distanciamiento entre la biografía histórica y el relato mítico, hay que apuntar que en la actualidad los artistas no diferencian entre la fuente de dónde proviene el material que emplean, sino que, sencillamente, "el relato se forma a partir de un material disociado, flotante, que se pega a la piel" (Chevrier, 2013, p. 26).

Por otra parte, cabe decir que la relación que se produce entre lo privado y lo público en el caso de este tipo de creadores, cuyas narraciones poseen un marcado cariz autobiográfico, es una cuestión en la que merece la pena detenerse. Estos artistas proyectan hacia el exterior sus reflexiones, sentimientos, deseos y especulaciones más privados. Y lo hacen de maneras muy distintas, como estamos observando, y con grados de encriptación también muy diferentes.

En la obra de Louise Bourgeois encontramos claros indicios de su autobiografía. En sus dibujos y pinturas de la década de 1940 aparecen cuerpos de mujer sin cabeza u otra parte o completamente sin torso, siendo sustituidos por casas. Muestra de ello es la obra Femme Maison (1946-47). En él se adivina ciertos aspectos de la biografía de Bourgeois. Su madre era quien llevaba su casa sobre los hombros, era la que aguantaba las infidelidades de su marido, pero a la vez era quien servía de elementos protector, de caparazón frente a estas circunstancias, para sus hijos. El recurso de la casa, como indica Charlotta Kotik:

(...) representa la topografía de nuestro ser más íntimo y se refiere a un espectro de experiencias relacionadas con el universo de nuestro primer domicilio. Humilde o lujoso, trágico o de crianza, las impresiones adquiridas en estas primeras salas, pasillos y escaleras de nuestros primeros años siempre vive dentro de nuestra imaginación. (Kotik, 1994, p. 22) 
Otro concepto que convendría traer a colación en relación a lo autobiográfico es el de Nachträglichkeit ("retroactividad" o "retrospectiva") mencionado en muchas ocasiones por Sigmund Freud y que recoge Nicola King en Memory, Narrative, Identity: Remembering the Self (2000). En este proceso el trascurso de la experiencia originaria se reconstruye a partir de las circunstancias del presente, no sólo con la pretensión de reconstruir la experiencia sino para dotarla de un nuevo sentido y de una eficacia psíquica que se ha desvanecido a causa de la represión de la experiencia (King, 2000). Así lo apreciamos en las obras de Frida Kahlo, como por ejemplo en la litografía Frida y el aborto (1932). En ella aparece un autorretrato rodeada de elementos pertenecientes a distintos momentos de su biografía: su hijo perdido, su incapacidad para andar, su vida dedicada a la pintura, su compleja relación amorosa con Diego Rivera, etc. En el caso de Kahlo, el arte que desarrolló se podría considerar como una tabla de salvación sobre la que amarrarse para tratar de sobrellevar todas estas circunstancias indeseables para ella.

\section{Huellas autobiográficas: el álbum familiar}

Refiriéndonos al terreno de la creación artística de índole autobiográfica podemos encontrar un tipo de obras que tratan de anclar la memoria a través de unas determinadas características que posee el objeto. Por lo que pudiéramos considerarlas como una suerte de vestigio que ha sobrevivido a la erosión que provoca el olvido y cuyas características sensoriales sirven de vehículo para trasladarnos a acontecimientos vividos en el pasado.

Uno de los medios de los que más se ha valido el arte y que representa este tipo de relación existencial con el objeto representado es la fotografía; sobre todo aquellas fotografías tomadas analógicamente, con anterioridad a la aparición de la fotografía digital, puesto que la naturaleza virtual de la imagen abre las puertas a una fácil alteración de la realidad fotografiada.

A continuación, analizaremos este tipo de obras y destacaremos algunos ejemplos realizados por mujeres artistas y en los que se evidencian otras particularidades como los autorretratos o sirven para exteriorizar algunos traumas pertenecientes a su memoria personal o colectiva.

\subsection{La memoria en la fotografía: la Fotografía Analógica}

Con la llegada de la cámara de pequeño formato al usuario de a pie la fotografía se convirtió en una inesperada herramienta para la documentación del ámbito de lo familiar y lo doméstico y en una auténtica fuente de reproducción de la memoria. La memoria pasaba así a estar en manos de un amplio sector social, democratizándose.

Este tipo de fotografías que hacen de testigos de un tiempo pretérito suelen recopilarse en los denominados álbumes de familia. Estos archivos personales sirven de registros de nuestra memoria autobiográfica y generan unas narrativas desde el momento en el comienzan a recopilarse las fotografías y ordenarse de acuerdo con un criterio.

Como indica la historiadora del arte María Rosón en Género, memoria y cultura visual en el primer franquismo (2016) la praxis de la fotografía personal está vinculada a la cultura femenina desde mediados del siglo XIX y es esencial esta práctica para entender la fotografía en la modernidad (Rosón, 2016). Sin embargo, este tipo de trabajos han sido invisibilizados debido a 
su carácter doméstico, íntimo y familiar. Características que se han vinculado con el "espacio de feminidad moderno" (Pollock, 2013).

Los relatos derivados de los primeros álbumes que conocemos están influenciados por las narrativas nacionales que acontecen en Gran Bretaña y sus colonias durante el siglo XIX (Chambers, 2001). Durante la época victoriana, la aparición de la fotografía hizo que se extendiera la imagen de familia blanca universal. Esto constituyó que tras la Segunda Guerra Mundial se produjera el llamado "The White flight" donde el prototipo de familia ideal se convirtió en un distanciamiento cultural y geográfico entre la raza blanca y otras como la negra, indígena, asiática, etc. (Chambers, 2001), fomentándose así una sociedad estamentaria en la que la raza blanca se encontraba en la cúspide.

Nombrando algunos ejemplos destacados de estos álbumes victorianos encontramos el elaborado por Mary Georgina Filmer. Su Filmer Album se constituye por interesantes collages fotográficos que interviene con acuarelas creando composiciones y escenas bastante originales. Dentro dicho álbum podríamos destacar una de las páginas sueltas que lo compone de mediados de la década de 1860 en el que aparece un retrato de la propia Lady Filmer cerca de una mesa sobre la que aparece un bote de pegamento y un álbum. Ella está rodeada por un lado del Príncipe de Gales ya que se suponía que los dos coqueteaban y de su esposa Sir Edmund Filmer y su perro.

Otro modelo de álbum victoriano es The Waterlow Album (1849-60 aproximadamente). Elaborado por Anne Waterlow evidencia la relación que tenía con sus hijos. Las páginas de dicho álbum están abarrotadas de fotografías. En algunas de ellas se atreve a hacer collages fotográficos, muchos de ellos mal cortados, con composiciones grupales donde Anne es el centro y la rodean sus hijos, llegándose incluso a ver los bordes de los recortes de esas imágenes. Es característico también la repetición de diferentes capturas de la misma pose como si le costara decirse por alguna de ellas y la aparición de imágenes borrosas o actitudes inusuales para la época victoriana. A modo de leyenda añade junto con las imágenes los nombres de las personas que aparecen y la fecha en la que pudo ser tomada la imagen. El orden que sigue el álbum es la presentación en primer lugar de los padres, dándole una especial relevancia al marido de Anne, Sidney Hedley Waterlow, seguido de las páginas de los hechos importantes de cada uno de sus hijos.

Como podemos comprobar, uno de los primeros usos populares que tuvo la fotografía fue el del registro conmemorativo de los acontecimientos familiares. El sociólogo Pierre Bourdieu en Un arte medio. Ensayo sobre los usos sociales de la fotografía (2003) dio un sentido a los álbumes familiares, entendiendo que actuaban como un compendio de imágenes con un claro valor historiográfico, en la medida en que

(...) puede aportar satisfacciones en cinco campos: la protección contra el paso del tiempo, la comunicación con los demás y la expresión de sentimientos, la realización de uno mismo, el prestigio social, la distracción o la evasión. Más concretamente, la fotografía tendría como función ayudar a sobrellevar la angustia suscitada por el paso del tiempo (...) (Bourdieu, 2003, p. 52).

La fotografía se convirtió así en un elemento de unificación social, en este caso en el seno de la familia. Incluso podría decirse que aquellos días en los que la familia se reunía entorno al álbum para recordar momentos pasados constituían, en sí mismos, una evidencia de la supuesta unidad 
familiar. Así lo pensaba al menos Susan Sontag, quien creía que ese repertorio visual contribuía a consolidar los lazos familiares, e incluso entre parientes cuya conexión o afinidad era bastante borrosa: "Mediante las fotografías cada familia construye una crónica de sí misma, un conjunto de imágenes portátiles que atestigua la solidez de sus lazos" (Sontag, 1996, pp. 18-19). Así, la fotografía, como vehículo para la rememoración del pasado, fomentará la imaginación debido a su doble cualidad: "Es a la vez una pseudopresencia y signo de ausencia" (Sontag, 1996, p. 26). La fotografía nos evade, nos retrotrae a otras épocas, revive la imagen de personas que tal vez ya no nos rodean y a la vez se presenta como una especie de objeto mágico que nos incitan a revivir situaciones o personas que ya no se encuentran entre nosotros.

El álbum familiar, al fin y al cabo, es una suerte de archivo organizado bajo unos criterios de selección determinados que está dedicado a registrar la historia familiar en forma de imágenes. La mayoría de ellos están configurados a partir de fotografías, pero existen variantes en las que se incluyen otra clase de objetos accesorios que se relacionan con la imagen fotográfica a la que acompañan (un mechón de pelo, una tarjeta, un lazo...). De hecho, en los orígenes de este tipo de recopilaciones, allá por la década de 1860, los álbumes "se nutrían de tarjetas de visita y otros tipos de retratos obtenidos en establecimientos comerciales reuniendo a varias generaciones en un orden vagamente cronológico" (Fontcuberta, 2013, p. 151). La elaboración del álbum supone, por lo tanto, un trabajo de la memoria, ya que la persona que recolecta los elementos que lo compondrán ha de realizar una labor arqueológica a través del desenterramiento de historias vividas y no contadas que pertenecen a individuos que, con frecuencia, pasan desapercibidos para la historia y la sociedad.

No obstante, de acuerdo con Julia Hirsch en Family Photographs: Content, Meaning and Effect (1981) los retratos familiares tienen una larga historia que se inicia en el Renacimiento. En este libro, Hirsch establece conexiones entre las convenciones del retrato familiar y la fotografía familiar ya que lo que evidencian es mostrar una familia ideal cuyas relaciones entre sus miembros son aceptables (Hirsch, 1997). Durante el siglo XX vamos a apreciar una evolución de la representación de la familia y del papel que desempeña la mujer en ella. Entre la década de 1910 y la de 1960 en la fotografía doméstica hubo un uso más popular entre la clase media de las sociedades occidentales. En ella se sigue percibiendo al marido con la responsabilidad de salvaguardar a su esposa e hijos, junto con la reputación externa de la familia (Goc, 2014). Por otro lado, y entre las muchas labores de la esposa se encuentra cuidar de la reputación interna de la familia. Este compromiso se manifiesta visualmente a través de la preservación de la memoria y la recopilación de aquellos momentos más significativos a través del álbum familiar o llamado también "Álbum Kodak" debido a la influencia del discurso que la empresa Eastman Kodak Company desarrolló en sus campañas publicitarias durante varias décadas (Goc, 2014). Incluso en sus campañas podemos destacar una evolución de la imagen de la mujer. Como indica Rosón, en 1889 se mostraba a través de la "Kodak Girl" una mujer moderna e independiente (Rosón, 2016) acompañada de su cámara y situada en distintas localizaciones bajo el slogan "Take a Kodak with you". Sin embargo, en la década de 1910, tras la I Guerra Mundial, el slogan era "At Home with KODAK" donde presentaba: “(...) imágenes de madres como fotógrafos familiares, promovió el papel de la mujer como tomadora, guardiana y, lo que es más importante, creadora del álbum familiar" (Goc, 2014, p. 53).

La mujer desde el ámbito doméstico al que se le relegó interiorizó la mirada patriarcal y se manifestó a través de la forma en que componían sus imágenes en el álbum familiar. Así lo comenta Marianne Hirsch: 
Las madres son los objetos de la mirada científico-social, que juzga la adecuación de su forma maternal detrás del espejo unidireccional en la sala de juegos del psicólogo. La mirada materna no es inobservada y, aunque sin duda puede ser considerada tan poderosa por quienes son sus objetos, se observa de cerca para asegurarse de que el empoderamiento real fluya de ella y no hacia ella. (Hirsch, 1997, p. 154)

La mujer que recopila este material sufre una suerte de represión autoimpuesta que trata de cumplir las expectativas de la sociedad que le rodea e inculcando a sus hijos una imagen de perfección y unos sueños y objetivos que no puede lograr para sí misma debido a su papel relegado a la sombra del ámbito del hogar. La teórica y líder feminista Betty Friedan analizó el papel de la mujer estadounidense en la década de los cincuenta en la cultura popular a través de las revistas y la publicidad sobre el que dedujo que estas imágenes hicieron que la mujer produjera una ama de casa que "se aleja de la identidad individual para convertirse en un robot biológico anónimo en una masa dócil. Ella se vuelve menos humana, se aprovecha de las presiones externas y se aprovecha de su esposo e hijos" (Friedan, 1963, pp. 296-297).

Este tipo de imagen de familia convencional se rompe en la década de los años cuarenta y cincuenta del siglo XX, cuando el concepto de familia comienza a redefinirse y, en consecuencia, a adoptar nuevas formas; una problemática que hace que la familia se convierta en objeto de estudio sociológico. Según otra autora, en este caso Marianne Hirsch, este cambio en el paradigma de la familia hace que no haya nada que pueda darse por sentado. Como cabe suponerse, en ese momento el álbum familiar empieza a sufrir una severa transformación que pone en declive su formato tradicional. Así, la fotografía revela las nuevas reorganizaciones familiares que abre sus fronteras más allá de factores biológicos, lo que pone de relieve el poder de autodefinición que poseen los miembros de una familia: "La 'familia' es un grupo de afiliación, y las afiliaciones que la crean se construyen a través de diversos procesos relacionales, culturales, e institucionales -como 'la mirada' y la fotografía, por ejemplo" (Hirsch, 1997, p. 10). Podríamos decir que el álbum familiar era como una especie de manifestación simbólica que trataba de perpetuar tal unidad. Una vez puesto en duda o desaparecido el tradicional pilar vertebrador, su apariencia mutó y, con ella, también el patrón tradicional del álbum familiar.

Zygmunt Bauman en su teoría del amor líquido nos habla acerca de cómo ha cambiado la manera de interactuar con los otros, e indica que hemos pasado de tener relaciones personales a tener conexiones (Bauman, 2005). Estas nuevas formas han influido inevitablemente en el concepto contemporáneo de familia. Sin embargo, en las imágenes que conforman el álbum familiar de hoy día se mantienen los mismos clisés de antaño. Parece como si el álbum se resistiera al cambio, al margen de ese nuevo tipo de relaciones interpersonales, y en sus páginas continuamos apareciendo alegres, continuamos acumulando momentos significativos que nos hicieron felices. La fotografía familiar nos hace recordar quiénes somos y determina cómo nos recordamos a nosotros mismos. El álbum familiar, podríamos convenir, contribuye a la construcción de nuestra memoria, tal y como subraya el teórico Don Slater, quien opina que la fotografía se ha convertido en uno de los pilares fundamentales de nuestra contemporaneidad, sobre el que se asienta nuestra identidad de manera estética y tecnológica (Vicente, 2013).

De hecho, los avances tecnológicos y digitales tanto en cámaras como en teléfonos móviles han propiciado la proliferación de imágenes de carácter biográfico, sobre todo en el plano virtual. En la actualidad se realizan millones de imágenes fotográficas cada día, que se comparten y se comentan a través de las redes sociales. Son imágenes en cierto modo objetualizadas, 
pues se intercambian como archivos no como experiencias vividas. Esto está trayendo como consecuencia un cambio en el foco de atención. Como indica el profesor y curador Pedro Vicente, desde la década de los setenta se ha venido produciendo un giro en los contenidos de lo fotografiado de lo social hacia lo autobiográfico, ya que la imagen está pasando de contar los eventos compartidos con nuestros parientes y allegados a relatar sobre nosotros mismos (Vicente, 2013). De la crónica que narra las experiencias de un colectivo familiar se está pasando a una autobiografía impregnada de lo cotidiano, donde el acto fotográfico se convierte en un hecho casi más importante que vivir la experiencia y que concluye almacenándose en memorias artificiales, memorias externas. Parece que, si no se fotografían las experiencias, estas no se han vivido. Se impone una necesidad de perpetuar y compartir a escala mundial ese "yo estuve aquí"; un proceso que nos lleva hacia una progresiva ficción subjetiva e idealizada de nosotros mismos y de los acontecimientos que vivimos. Es lo que Juan Martín Prada calificó como un nuevo régimen de la mirada:

El ver no es sólo acto o experiencia, ahora es, simultáneamente, registro técnico, fijación en memoria externa. Son esas posibilidades del registro las que prevalecen en detrimento de las de la experiencia misma, que ya no suele ni siquiera darse (cámaras de vigilancia permanente que no son atendidas, webcams emitiendo sin que sus datos sean visualizados por nadie...). Lógicas en definitiva de la ausencia tras la cámara y precesión, pues, del registro técnico, de la archivación digital, frente a la mirada. (Martín Prada, 2010, p. 41)

¿Cómo se articulan entonces hoy los álbumes familiares? Armando Silva (2013) destaca que se han de dar cuatro componentes para que exista un álbum familiar: "la familia; un objeto que hace posible mostrarla visualmente: la fotografía, (...) un modo de archivar estas imágenes: el álbum de fotografías; (...) el álbum cuenta historias" (p. 21). Sobre esta declaración habría que puntualizar o añadir otro componente esencial y es el que estamos tratando de defender en este artículo y es el papel de la mujer como hacedora de los álbumes familiares. La importancia de la compiladora de estas imágenes es fundamental porque gracias a ella se pueden entender las narrativas que se derivan de lo que acontece en las fotografías desde prácticas, tradiciones y significados (Ortiz, 2005).

La familia como colectivo ha ido experimentando también su propia evolución. Si bien en un principio aludía a las personas que se encontraban a cargo del pater -en la antigua Roma, incluyendo a los esclavos-, después pasó a vincular solamente a quienes compartían lazos de sangre entre sí. La evolución de este grupo social, mostrada a través de la fotografía, permite ver cómo ha ido evolucionando la definición de familia, desde los rígidos gestos y posturas victorianas a los momentos kodak, en los que se registraban poses y enclaves más desenfadados. Muestra del inicio de este cambio de percepción en torno a este tipo práctica es la exposición The Family of Man que en 1955 organizó el curador Edward Steichen en el MOMA de Nueva York. En esta muestra se evidenciaba los caracteres comunes de las familias de todo el mundo a la hora de recoger momentos importantes de sus biografías a través de la fotografía.

El álbum, como archivo, se configura mediante la recopilación de las imágenes, de su orden y configuración y de ello resultará el relato de nuestra propia vida. Una narración que, no en vano, ofrece la posibilidad de reordenar, añadir y manipular los detalles y los acontecimientos a quien posee dicho álbum, permitiendo nuevas lecturas del mismo. Como dice la curadora Nuria Enguita respecto al álbum familiar: "participa del teatro y de la literatura por la existencia de 
un argumento y de unos protagonistas, y sobre todo por la inclusión de la voz de un narrador o el autor" (Enguita Mayo, 2013, p. 115). La actividad recopiladora del autor-narrador se desarrolla desde la intimidad. Sin embargo, el acto de mostrarlo y/o de narrarlo se enfoca hacia lo público, aunque no exista en primer término una pretensión de que el conjunto fotográfico sea considerado como arte. Aparte, esas imágenes que componen el álbum nacen de un acto bastante teatralizado que "se produce delante y detrás de la cámara, antes y después de hacer la fotografía. (...) todos representamos lo que somos, nos convertimos en actores de nuestras propias vidas" (Vicente, 2013, p. 13). Las personas fotografiadas muestran su identidad hacia el exterior de forma mediatizada, con poses estereotipadas e influidas por convencionalismos sociales y culturales. Por lo que, a nuestro juicio, el álbum familiar constituye una gran mascarada de poses y actitudes, de actores que sustituyen a la verdadera persona. Las escenas se localizan tanto en exteriores como en interiores, pero sin dejar de estar vinculados a acontecimientos importantes o dignos de ser recordados.

El interés por las narraciones derivadas de lo cotidiano comienza a reavivarse y revisarse a partir de la década de los sesenta del siglo XX, de acuerdo con el texto Sweet it is to Scan...: Personal Photographs and Popular Photography (2015) de Patricia Holland. Ello es debido a los profundos cambios sociales que se estaban produciendo en las sociedades occidentales. Feministas, historiadores y artistas entre otros colectivos, empiezan a releer las historias derivadas de las fotografías cotidianas para tratar de comprender la historia, pero ahora analizándola desde su propia biografía. En ese proceso interviene el factor temporal, como indica Nuria Enguita. Según ella, aparece un tipo de tiempo circular, ya que desde el presente se relatan los eventos pasados y se profetizan acciones futuras, regresando de nuevo al presente (Enguita Mayo, 2013). No es un relato cerrado, sino que se van añadiendo detalles cada vez que se narra. Por lo que existe una continua actualización de esos acontecimientos, renovada desde el presente. Otro de los factores que interfieren es el de la selección de las imágenes. Como decíamos -y ponemos por caso el de la artista Inmaculada Salinas- los realizadores de dichos álbumes ordenan y seleccionan las imágenes, con la potestad de poder eliminar aquellos acontecimientos que no se desean recordar.

En sintonía con Pedro Vicente, a quien ya nos hemos referido en este apartado, se encuentran las consideraciones sobre la fotografía de álbum familiar que vierte Patricia Holland en su texto anteriormente mencionado, donde diferencia entre dos tipos de lectura, la del usuario y la del lector:

Los usuarios aportan a las imágenes una riqueza de conocimientos circundantes. Sus propias imágenes privadas forman parte de una compleja red de recuerdos y significados con los que dan sentido a su vida cotidiana. Para los lectores, por otra parte, una foto borrosa o un retrato sonriente a partir de los años 50 es un texto misterioso cuyos significados se deben tomar en un acto de la descodificación o del trabajo detective histórico. Los usuarios de imágenes personales tienen acceso al mundo en el que tienen sentido; Los lectores deben traducir esos significados privados en el conocimiento del rico suelo de significados que los mantiene en su lugar (Holland, 2015).

Sobre las nuevas concepciones de la familia, de lo familiar y cotidiano, quisiéramos destacar el álbum realizado por la artista Esperanza Parada (1928-2011) y que analiza pormenorizadamente María Rosón en el libro anteriormente mencionado. Las peculiaridades de este álbum no son sólo debido a que su realización abarca un periodo singular desde que antes de que la propia Esperanza naciera hasta el final de la juventud, sino que nos ofrece además una 
(...) "escritura del yo" en la que tienen una enorme importancia la genealogía, la amistad y la sororidad, frente al amor romántico, lo que supone una ruptura de la norma social y cultural que imperó en relación a la socialización femenina durante la dictadura. (Rosón, 2016, p. 275)

Parada configuró un álbum que en apariencia poseía unas características con las que pretendía lograr cierta atemporalidad, ya que estaba encuadernado en cuero y la disposición de las fotografías subrayaban su sentido háptico, es decir estaba pensado para tocarse ya que no estaban cubiertas ni metidas en fundas de plástico (Rosón, 2016). Esta necesidad de querer trascender el tiempo también se muestra en las notas manuscritas que aparecen junto a las fotos y que ayudan a saber quiénes son las personas que aparecen. De esta manera, en el momento en el que Esperanza no estuviera, alguien podría leer el álbum y comprender lo que acontecía en esas fotografías. En él podemos ver como ella renunció a su propia carrera de pintora para tratar de ayudar a su marido y también artista, Julio López Hernández, trabajando en la Galería Juana Mordó. Clave en el desarrollo artístico de la modernidad española. En sus imágenes vemos desde sus padres, parientes, amistades y otros artistas del grupo los Realistas de Madrid, además de todas las personalidades que fue conociendo, por lo que se convierte además en un depósito cultural de incalculable valor.

Junto a este ejemplo podemos encontrarnos el trabajo de otras artistas que evidencian nuevas intencionalidades a la hora de configurar el álbum familiar y que subvierten los convencionalismos en torno a la idea de lo feminino. Muestras de ello son, por un lado, Nan Goldin y su especie de contra-álbum personal, The Ballad of Sexual Dependency (1980-86) donde no aparecen momentos felices, sino que se representan discusiones, violencia, muerte, etc. Convirtiéndose en un registro detallado de un momento específico de la biografía de la artista que le permitió tener control sobre su vida y recordar lo que vivió. Y, por otro lado, Inmaculada Salinas, que se interesa por lo que esconde el álbum familiar con objeto de penetrar en el repertorio implícito de propaganda familiar, trascendiendo el concepto. Para ello se hizo con un extenso banco de imágenes de diferentes lugares europeos y elaboró una narración biográfica dando lugar a la serie Microrrelatos en rojo (2012). Para cada una de las imágenes del álbum se sirvió de composiciones de tres fotografías: "la primera es la que aparece en la primera hoja del álbum familiar, la segunda es la que la narradora escoge como la más significativa según su criterio y la tercera es la que aparece al final, en la última hoja del álbum" (Salinas citada en Enguita Mayo, 2013, p.134). Además de la selección que ella realiza, focalizada en la figura femenina, aparecen textos que hablan sobre la crudeza de las relaciones familiares. Como podemos observar a la hora de elaborar una narración visual, además de los ingredientes visuales o textos, la ordenación y selección de las imágenes son de vital importancia para dotar a la lectura de un sentido determinado.

La narración resultante de esa disposición de las fotografías en el álbum estará vinculada a nuestra propia identidad. Durante el proceso de ordenación, contextualización espacio-temporal y reconocimiento de los personas que en ellas aparecen dará como resultado una narración bio o autobiográfica. Este acto es lo que denomina Martha Langford como "contar el álbum" (Langford, 2013, p. 63). En el momento en el que este álbum es sacado y deja de pertenecer a la comunidad, las imágenes dejan de evocar esos relatos orales que en realidad no son sino la estructura, la historia, sobre la que se asienta un colectivo. Y esas historias son, al fin y al cabo, las que dotan de una verdadera configuración al álbum. A partir de estas narraciones se conocen a otros miembros familiares, de otras épocas o lugares, algunos que ni siquiera hemos 
llegado a conocer, y mediante la observación de la evolución fisionómica de los retratados se transita por el paso del tiempo. Los álbumes fotográficos son una fuente de información esencial para conocer y comprender nuestra memoria individual y colectiva. Estos relatos poseen la capacidad de añadir recuerdos a momentos que no hemos vivido pero que, sin embargo, hemos heredado a partir de los que nos han contado otros, a partir de las fotografías. Como indica Gustavo Puerta, los álbumes familiares poseen un indudable componente biográfico vinculado a lo narrativo debido a que acontecen determinadas características para que tenga lugar un relato, por lo que

\section{(...) pueden ser incluidos dentro de la literatura memorialista. No sólo por su carácter biográfico, por fijar recuerdos y alentar la construcción de una memoria compartida, sino también por su dimensión narrativa: por crear una unidad temporal que sintetiza lo heterogéneo en una acción total y completa, por disponer de un principio organizador que confiere a la narración un orden, por articular una estructura cronológica en secuencias, subtramas, capítulos, (...). (Puerta Leisse, 2013, p. 87)}

Este proceso de narración derivada del álbum concede una importancia relevante a los procesos de selección y ordenación de las imágenes. Tal es así que la artista neoyorkina Zoe Leonard configura un archivo titulado The Fae Richards Photo Archive, realizado entre 1993-1996. Su propuesta supone un ejercicio de apropiacionismo ya que se sirve de la descontextualización y posterior recontextualización para hablar de otras cuestiones que atañen a la memoria colectiva y a la historia a partir de la memoria individual. Leonard, a través de la acumulación de imágenes procedentes de entre las décadas de los años veinte y setenta, y en colaboración con la cineasta afroamericana Cheryl Dunye presenta una biografía ficticia de una actriz de raza negra y lesbiana. La recreación de una biografía visual desde la ficción hace colocar el dedo en la llaga debido a la situación por la que atraviesan determinadas minorías sociales en países occidentales como los Estados Unidos.

Otro ejemplo de narración derivada de un álbum familiar es el aportado por la artista Jo Spence y que expuso en la galería londinense Hayward en 1979 bajo el título Beyond the Family Album. En esta muestra se revisaba su álbum familiar y lo deconstruía críticamente, en un ejercicio que ella denominó como "autobiografía visual" (Kuhn, 2013, p. 101). Jo Spence junto con Rosy Martin establecieron unos protocolos interesantes para abordar sus particulares fototerapias, que Kuhn recogió en "Otra mirada a Family Secrets":

1. Examine el/los sujeto(s) humano(s) de la fotografía. Comience con una descripción somera para adentrarse después en un relato en el que usted se pondrá en el lugar del sujeto. En esta parte del ejercicio resulta útil recurrir a la tercera persona (por ejemplo, ella mejor que yo). Para hacer aflorar los sentimientos asociados a la foto, visualícese tal y como era el sujeto en aquel momento -en la imagen-, lo que podrá ir haciendo a su vez con todos los sujetos humanos de la foto, si hubiera más de uno, e incluso con los animales o los objetos inanimados.

2. Examine el contexto de producción de la imagen. Dónde, cuándo, cómo, por quién y por qué se tomó la fotografía.

3. Examine el contexto en el que debió de tomarse una imagen de este tipo. ¿Qué tecnología fotográfica se emplearía? ¿Cuál es la estética de la imagen? ¿Se adapta a determinadas convenciones fotográficas? 
4. Examine la misión de la foto en su contexto o contextos de recepción. ¿Para quién o para qué se hizo esa foto? ¿Quién la tiene en este momento y dónde se guarda? ¿Quién la vería entonces y quién la ve ahora? (Kuhn, 2013, p. 105)

Como ellas mismas indican, a partir de su metodología, a través de la práctica terapéutica de una acción que partía del álbum familiar, pudieron adentrarse en los confines de la subjetividad, analizando pormenorizadamente los hechos que rodeaban a cada fotografía, cada fragmento de su historia. Para afrontar dicho proyecto se dedicó a recopilar y disponer posteriormente en paneles fotografías personales, recortes de prensa y textos autobiográficos. La pretensión era poner de manifiesto aquellas experiencias traumáticas que no se reflejaban en los álbumes familiares convencionales como muertes, divorcios, enfermedades, etc. De esta manera se conseguía establecer un distanciamiento frente a los estereotipos que reflejaban las imágenes tradicionales del álbum familiar y tomar las riendas de un nuevo tipo de recopilación biográfica, que hasta entonces no era usual.

La respuesta a lo convencional y a la naturaleza estándar de las representaciones que aparecen en los álbumes familiares hace que las coordenadas espacio-temporales sean eliminadas, haciendo que incluso se desvanezcan los rasgos característicos de las personas representadas. Al ver imágenes de otros álbumes que no sean los nuestros podemos ver cómo las poses, encuadres y la forma de mirar a la cámara se van repitiendo, independientemente de quien sea la familia. Sucede igual con las personas que aparecen, aunque no los conozcamos porque ya han fallecido y no pertenecen a nuestro tiempo vital o porque sencillamente sean individuos completamente anónimos para nosotros, esos rostros, a veces turbios o desdibujados, nos recuerdan a otras personas o familiares que sí conocemos.

La capacidad de encontrar conexiones entre la memoria de lo vivido por el espectador y lo que se representa en la fotografía, es lo que denominó Walter Benjamin como inconsciente óptico -idea que trató en Historia de la Fotografía y en La obra de arte en la era de su reproductibilidad técnica-. A este concepto llegó tras considerar que la cámara (fotográfica o cinematográfica) proporcionaba una serie de recursos -como la posibilidad de ampliar los detalles o de capturar el movimiento- que permitían que el ojo humano se percatara de detalles en los que no podría reparar de otra forma. Así, refiriéndose a la cámara, dijo: "Sólo gracias a ella tenemos la experiencia de lo visual inconsciente, del mismo modo en que, gracias al psicoanálisis, la tenemos de lo pulsional inconsciente" (Benjamin, 2003, pp. 86-87). Según Benjamin, ese inconsciente óptico va a interferir en nuestros procesos perceptivos conscientes, trazando lazos invisibles entre las imágenes fotográficas y lo almacenado en la memoria visual inconsciente.

Este concepto de inconsciente óptico tiene cierta relación con lo que Marianne Hirsch denominó como mirada afiliativa (affiliative look) en su libro Family Frames (1997). Esta mirada afiliativa repercute en el espectador, quien trata de incorporar a su memoria los aspectos narrativos derivados de las visualizaciones de los recuerdos capturados a través del álbum familiar. Pues a pesar de que la visualización de imágenes familiares ajenas pudiera carecer de interés o emoción para quien lo visualiza, lo cierto es que la incorporación que inconscientemente hacemos de nuestro relato familiar a él hace que se revitalice nuestra memoria visual acumulada, dado que resulta inevitable evadirnos del repertorio de tipos y poses arquetípicas que hemos ido grabando en nuestra retina desde que aparecieron los retratos familiares. Y es que la memoria, como sugiere M. Hirsch, es la combinación visual del espacio y del tiempo junto con su dimensión verbal (Hirsch, 1997) y se convierte en lo que Mitchell denominó como imagentexto: "un 
sistema de código-doble para el almacenaje y recuperación mental que puede utilizarse para recordar cualquier secuencia de cosas, desde historias, a discursos o listas de cuadrúpedos" (Mitchell, 2009, p. 171). De esta forma tanto imágenes como textos hacen de instrumentos para la memoria, ayudando a que sus contenidos pervivan.

Jugando con esta mirada afiliativa sobre las poses y tipos que tenemos interiorizados a partir de las visualizaciones de nuestro álbum familiar y junto con alto grado de perfomatividad, nos topamos con la obra de la artista británica Gilliam Wearing. En especial con la titulada Album (2003) donde construye una serie de imágenes para las que parte de una selección de fotografías de su álbum personal en las que los miembros de su familia poseen la misma edad aproximadamente. Para ello escenificó las localizaciones de las fotos originales, adoptó sus poses e hizo una máscara de silicona de cada uno de ellos, incluso de ella misma, sobre las que se coloca la propia Wearing, poniendo de manifiesto las similitudes genéticas heredadas del parentesco. Sin embargo, el único elemento de ella que pervive en sus retratos escenificados son sus ojos que no son cubiertos por las máscaras, convirtiéndose sus retratos en unos ejercicios de extrañamiento:

Hay algo entre siniestro y nostálgico cuando a cierta edad empezamos a reconocer en nuestro rostro algún gesto de nuestros padres, y esa realidad anacrónica que nos devuelve a otro tiempo y a otra realidad somos conscientes de que cada retrato no es sólo semejanza, sino también índice, huella de algo que no se ve, pero que también nos pertenece. (Enguita Mayo, 2013, p. 131)

Quisiéramos destacar otro de los conceptos desarrollados por Hirsch en el libro anteriormente mencionado. Si bien su aplicación puede extenderse a cualquier tipo de obra artística, si consideramos pertinente ejemplificar su idea de postmemoria a través de la fotografía y el álbum familiar. Dicho concepto está basado en la idea de recolección heteropática (heteropathic recollection) de la historiadora Kaja Silverman, consistente en que uno es capaz de adoptar recuerdos similares de otra persona a través de un proceso de identificación heteropática, a través de un método en cual un individuo toma los recuerdos de otro. Hirsch (1997) ha elaborado sobre el concepto de recolección heteropática el concepto de postmemoria en el cual

(...) se distingue de la memoria por la distancia generacional y de la historia por la profunda conexión personal. Postmemoria es una forma poderosa y bastante particular de la memoria, precisamente por su conexión con su objeto o fuente no está mediada a través de recogimiento sino a través de una inversión de imaginación y creación. Esto no quiere decir que la memoria misma no posea mediación, sino que está más directamente relacionada con el pasado. Postmemoria caracteriza a la experiencia de los que crecen dominados por las narrativas que precedieron a su nacimiento, cuyas propias historias tardías son evacuadas por las historias de la generación anterior en forma de eventos traumáticos que no pueden ser comprendidos ni recreados. (Hirsch, 1997, p. 22)

Entendemos por lo tanto que la postmemoria es una clase de memoria que se relaciona directamente con el hecho narrativo. Es una memoria que rescata el pasado a partir del imaginario colectivo existente y de aquello que ha perdurado a través de las generaciones (ya sea en imágenes o mediante narraciones escritas u orales). Para estos tipos de recuerdos almacenados la imaginación posee un rol fundamental, pues hilvana los retazos de memoria de un hecho o unas circunstancias lejanas en el tiempo y por lo general traumáticas. 
Este concepto ha repercutido estéticamente en la imagen contemporánea y en especial en aquellos trabajos basados en la recuperación de personajes o acontecimientos del pasado realizados mediante la fotografía o a partir de ella. Así, en la reivindicación de los vacíos que dejaron esas personas, algunos artistas harán especial hincapié en la forma de representar esas personas ausentes. En este sentido destacamos a la artista argentina Lucila Quieto que desarrolló un ensayo fotográfico entre 1999 y 2001, llamado Arqueología de la ausencia. Se trata de una serie fotográfica de 35 imágenes, de las cuales muchas de ellas están protagonizadas por la propia artista. Para dicho proyecto recopiló fotografías de su álbum familiar en las que aparecía su padre. Quieto no llegó a conocerlo ya que nació después de haber sido secuestrado y desparecido por parte de la dictadura argentina (1976-83). La ausencia de su padre y de otros desparecidos de la dictadura es el germen de este proyecto. Ella se autorretrató proyectándose sobre sí misma imágenes de su álbum. Por lo que consiguió tener esa imagen conjunta que nunca pudo tener y la presencia de su padre en forma de luz proyectada sobre su cuerpo. Esta metodología le llevó a colocar un anuncio en la sede HIJOS (Hijos por la Identidad y la Justicia contra el Olvido y el Silencio) que decía: «Si querés tener la foto que siempre soñaste y nunca pudiste tener, ahora es tu oportunidad, no te la pierdas. Llamame» (Fortuny, 2014, p. 86) y consiguió que otras personas que estaban sufriendo el mismo tipo de duelo que Quieto les llevara a participar contribuyendo con las imágenes de sus respectivos álbumes y apareciendo con esas ausencias de la dictadura proyectadas sobre sus cuerpos. Dando como resultado una obra colaborativa que se nutre del trauma para tratar de superarlo o convivir con él. 


\section{CONCLUSIONES}

A partir de todo lo que hemos expuesto en esta investigación, podemos decir que el papel de la mujer en la custodia de nuestra memoria autobiográfica es fundamental. Ella se ha encargado principalmente de la elaboración de estos archivos visuales y para ello ha tenido que seleccionar, recopilar y ordenar aquellos momentos destacados de la vida de sus familiares y allegados, conformando así una narración esencial para la configuración de nuestra identidad a través del empleo de los álbumes familiares.

El desempeño de este rol puede ser aplicado a todas aquellas artistas que han trabajado en las elaboraciones de álbumes. Sus trabajos han permitido la exteriorización autobiográfica a través de determinados tipos de imágenes y han dado visibilidad a muchas problemáticas y temas que la sociedad ha ocultado o no han sido adecuadas para que fueran protagonizadas por mujeres, como por ejemplo el deseo y la sexualidad femenina, los estragos de la enfermedad o traumas familiares a causa de la violencia ejercida hacia ellas o bien por acontecimientos políticos que han quebrantado la unidad familiar.

Determinados tipos de obras artísticas de corte narrativo y conceptual que beben de la memoria individual han sufrido el descrédito tanto por parte de tendencias artísticas que hablaban desde un punto de vista metalingüístico como por parte de otras ramas del conocimiento, ya que consideraban estos trabajos como discursos personales que carecían de datos contrastables y verídicos. Sin embargo, este tipo de micronarrativas se interrelacionan, enriquecen y configuran lo que va a ser la macronarrativa de la historia. A fin de cuentas, estos relatos individuales hechos a partir de la ordenación de las fotografías del álbum familiar hablan de mitos y rituales, que no son sino formas de crear cultura y enfrentarse a nuestro yo actual.

Por otro lado, este tipo de manifestaciones han dado voz a traumas personales vividos en primera persona o partir de los que nos han contado nuestros predecesores. Son lo que vienen a ser relatos derivados de la postmemoria. A lo que hay que añadir que, en cierta forma, cumple un rol de sublimación de lo traumático y el arte se torna en una suerte terapia compartida que puede llegar a representar o conceptualizar los conflictos psicológicos de muchas personas a través de imágenes. 


\section{REFERENCIAS}

Bauman, Z. (2005). Amor Líquido. Acerca de la fragilidad de los vínculos humanos. Madrid: Fondo de Cultura Económica.

Béguin, A. (1952). Preface to Oeuvres by Gerald Nerval. Paris:

Gallimard.

Benjamin, W. (2003). La obra de arte en su época de la reproductibilidad técnica. México D.F.: Ítaca.

Borja-Villel, M., 2013. Texto presentación. En: Formas Biográficas. Construcción y mitología individual (pp. 7-11) Madrid: Museo Nacional Centro de Arte Reina Sofía.

Bourdieu, P. (2003). Un arte medio. Ensayo sobre los usos sociales de la fotografía. Barcelona: Gustavo Gili.

Chambers, D. (2001). Representing the Family. Londres: Sage Publications.

Chevrier, J. F. (2013). Formas Biográficas. Construcción y mitología individual. Madrid: Museo Nacional Centro de Arte Reina Sofía. Siruela.

Conway, M. A. et al. (2002). Brain imaging autobiographical memory, The Psychology of Learning and Motivation, 41, 229263.

Enguita Mayo, N. (2013). Narrativas domésticas: más allá del álbum familiar. En P. Vicente (Ed.), Álbum de familia. [re] presentación, [re]creación e [in]materialidad de las fotografías familiares (pp. 115-136). Madrid: Diputación de Huesca. La Oficina.

Fontcuberta, J. (2013). Monumentalizar el álbum: dos casos de estudio. En P. Vicente (Ed.), Álbum de familia. [re]presentación, [re]creación e [in]materialidad de las fotografías familiares (pp. 151-162). Madrid: Diputación de Huesca. La Oficina.

Fortuny, N. (2014). Memorias fotográficas. Imagen y dictadura en la fotografía argentina contemporánea. Buenos Aires: La Luminosa.

Friedan, B. (1963). The Feminine Mystique. Nueva York: Dell.

Gibbons, J. (2007). Contemporary art and Memory. Images of 
Recollection and Remembrance. Londres: I.B. Tauris.

Goc, N. (2014). Snapshot Photography, Women's Domestic Work, and the "Kodak Moment", 1910s-1960s. En E. Patton y M. Choi (Eds.) Home sweat home: perspectives on housework and modern relationships (pp 27-48). Plymouth: Rowman \& Littlefield.

González, M. P. y Pagès, J. (2014). Historia, memoria y enseñanza de la historia: conceptos, debates y perspectivas europeas y latinoamericanas. Historia y Memoria, 9, 275-311. Recuperado de http://www.scielo.org.co/scielo.php?script=sci_arttext\&pid=S2027$51372014000200010 \&$ Ing=en\&tlng=es.

Hirsch, M. (1997). Family Frames. Photography narrative and postmemory. Londres: Harvard University Press.

Holland, P. (2015). Sweet it is to Scan...: Personal Photographs and Popular Photograph. Nueva York: Routledge. Taylor \& Francis Group.

Hume, D. (2001). Tratado de la naturaleza humana. Albacete: Servicios de publicaciones. Diputación de Albacete.

Huyssen, A. (2002). En busca del futuro perdido. Cultura y memoria en tiempos de Globalización. Buenos Aires: Fondo de Cultura Económica.

King, N. (2000). Memory, Narrative, Identity: Remembering the Self. Edimburgo: Edimburgh University Press.

Kotik, C. (1994): The Locus of Memory: An introduction to the work of Louise Bourgeois. En J. Ekman (Ed.), Louise Bourgeois: The Locus of Memory, Works 1982-1993. Nueva York: The Brooklyn Museum.

Kuhn, A. (2013). Otra mirada a Family Secrets. En P. Vicente (Ed.), Álbum de familia. [re]presentación, [re]creación e [in]materialidad de las fotografías familiares (pp. 101-114). Madrid: Diputación de Huesca. La Oficina.

Langford, M. (2013). Contar el álbum: una aplicación del marco oralfotográfico. En P. Vicente (Ed.), Álbum de familia. [re]presentación, [re]creación e [in]materialidad de las fotografías familiares (pp. 6381). Madrid: Diputación de Huesca. La Oficina,.

Martín Prada, J. (2010). La condición digital digital de la imagen. En LÚMEN-EX. Premios de Arte Digital. Universidad de Extremadura (pp. 41-53). Cáceres: Universidad de Extremadura.

Millán, M. (2016). Entrevista a Enzo Traverso. Cuadernos de 
Marte, [S.I.], n. 11, 265-278, dic. 2016. Recuperado de https:// publicaciones.sociales.uba.ar/index.php/cuadernosdemarte/ article/view/2128

Mitchell, W. J. T. (2009). Teoría de la imagen. Madrid, España: Akal / Estudios visuales.

Ortiz, C. (2005): Fotos de familia: los álbumes y las narrativas domésticas como forma de arte popular. En A. Cea Gutiérrez, C. Ortiz García y C. Sánchez Carretero (Eds.), Maneras de mirar: lecturas antropológicas de la fotografía (pp. 189-210). Madrid: CSIC.

Pollock, G. (2013): "Modernidad y espacios de la feminidad". En Visión y diferencia. Feminismo, feminidad e historias del arte (pp. 111-163). Madrid: Fiordo.

Puerta Leisse, G. (2013). La construcción de la infancia en el álbum familiar. En P. Vicente (Ed.), Álbum de familia. [re] presentación, [re]creación e [in]materialidad de las fotografías familiares (pp. 83-88). Madrid: Diputación de Huesca. La Oficina.

Rimbaud, J. A. (2006). http://www.biblioteca.org.ar/. [Online] Recuperado de http://www.biblioteca.org.ar/libros/133650.pdf.

Rosón, M. (2016). Género, memoria y cultura visual en el primer franquismo (materiales cotidianos, más allá del arte). Madrid: Cátedra.

Saltzman, L. (2006). Making memory matter. Strategies of Remembrance in Contemporary Art. Chicago: The University of Chicago Press.

Sarlo, B. (2005). Tiempo pasado. Cultura de la memoria y giro subjetivo. Una discusión. Madrid: Siglo XXI.

Silva, A. (2013). Álbum: deseos de familia. En P. Vicente (Ed.), Álbum de familia. [re]presentación, [re]creación e [in] materialidad de las fotografías familiares (pp. 21-31). Madrid: Diputación de Huesca. La Oficina.

Sontag, S. (1996). Sobre la fotografía. Barcelona: Edhasa.

Troncoso, L. y Piper, I. (2015). Género y memoria: articulaciones críticas y feministas. En Athenea Digital: Revista de Pensamiento e Investigacion Social, 15(1), 65-90. Recuperado de https://www. researchgate.net/publication/276889487 
Vicente, P. (2013). Apuntes a un álbum de familia. En P. Vicente (Ed.), Álbum de familia. [re]presentación, [re]creación e [in] materialidad de las fotografías familiares (pp. 11-19). Madrid: Diputación de Huesca. La Oficina.

Warnock, M. (1987). Memory. Londres: Faber \& Faber.

White, H. (1992). Metahistoria. La imaginación histórica en la Europa del siglo XIX. México: Fondo de Cultura Económica. 